\title{
UM ORIENTALISMO ESCLARECIDO? AS LENDAS DA ÍNDIA DE LUÍS FILIPE CASTRO MENDES
}

\author{
Duarte Drumond Braga \\ (CentrodeEstudosComparatistas, UniversidadedeLisboa)
}

Lendas da Índia (Dom Quixote, 2011), do poeta português Luís Filipe Castro Mendes (doravante LFCM) (n. 1950), é fruto de uma estada em New Delhi onde, diplomata de carreira, o autor presentemente já não se encontra. Depois de dez anos sem publicar, o Oriente parece ser responsável pela revitalização do seu trabalho poético, como em outros casos relativamente recentes. Lembremos o ciclo macaense (19871991) do recém-falecido António Ma-

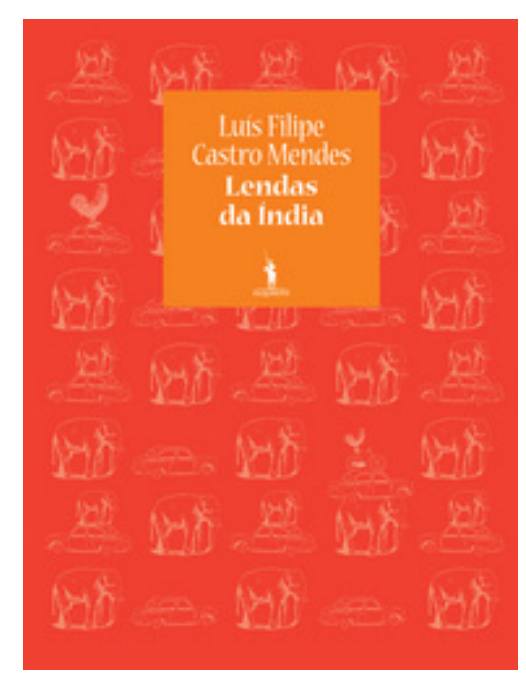
nuel Couto Viana, pelo qual se abriram novos trilhos; e ainda - sem dúvida com alcance e implicações mais profundas do que nos outros dois - o caso de Ruy Cinatti.

No que toca à experiência da Ásia que este livro recolhe, será sem dúvida o ar pós-colonial e multicultural do nosso tempo (e suas articulações com o campo das relações internacionais) que obriga esta poesia a nascer com várias precauções ideológicas. Começando, antes de mais, por um desmascarar de estereótipos ("Enquanto alguns pensam que a Índia é um país/ de milionários e de faquires...”, [MENDES, 2011, p. 53]), dá-se neste livro uma ultrapassagem do modo exótico, que o autor diz aliás não sobreviver para o europeu mais do que duas monções (V. secção do livro intitulada "A Terceira Monção"). É certo que o autor recusa tal registo, embora acabe por ceder a glosar velhos tópicos que dominaram a visão europeia da Ásia ao longo dos séculos XIX e XX, e de que falo em breve: o cansaço face ao Oriente e sua impenetrabilidade.

De qualquer modo, o poeta assume, desde os primeiros textos do livro, a complexidade e o carácter multiplanar do objecto chamado Índia, também no caso particular de uma história de "contactos" que não se deu 
apenas entre indianos e portugueses. É assim que a textualidade confusa de que essa História se constitui por vezes corresponde, nesta obra, a momentos polifónicos:

O historiador indiano conta pormenores: vem tudo nas crónicas, assevera, não se entende como os ingleses se enganaram no local e foram construir um mamarracho comemorativo, a dez quilómetros daqui! «Basta ler as crónicas portuguesas» insiste o Professor John "para reconhecer o lugar certo». (“Calicute: aqui desembarcou Vasco da Gama" [MENDES, 2011,p. 14])

Ao mesmo tempo, estes versos já permitem supor aquilo que ao longo do livro cabalmente se confirma: o exorcismo do remorso pós-colonial, quer da parte do europeu, quer da do indiano de hoje. Esta postura dá, por sua vez, origem a uma constante ironia face à ideologia celebratória da multiculturalidade. A superação daquele discurso (entre um certo pós-colonial e um certo multicultural) passa, ora por um pragmatismo diplomático, bem ciente das circunstâncias do mundo actual - Cf. "1498: Modernidade do Samorim", (MENDES, 2011, p. 127) -, ora por um humanismo universalizante, que procura uma simpatia (no sentido etimológico do termo), mesmo no auge do estranhamento:

(...) íamos a meditar em coisas muito sérias e muito hindus e multiculturais.

Mas de repente tudo o que nos rodeava perdeu o seu sentido, porque anoitecia simplesmente (....)

São momentos em que entendemos que somos da mesma gente, neste país de tão diversa gente...

(“Anoitecer no Ganges" [MENDES, 2011, p. 18-19])

Para o primeiro dos casos, temos a figura simbólica de um Samorim - o personagem histórico que recebeu Vasco da Gama em 1498 - "modernizado" (como o sujeito poético diz), mas que não o é nem enquanto anacrónico freedom fighter pós-colonial (no sentido anti-colonial do termo), nem uma figura sem existência real fora da sua fixação mítica n’Os Lusíadas. Eis o poema completo:

Não causou estranheza ao Samorim que o Gama usasse com ele o verbo «descobrir»:

tinham menos sensibilidade colonial aqueles reis e o «olhar antropológico» era para eles uma questão de mercado.

É verdade que o verdadeiro mundo colonial só veio depois. Subramanyam estranha que o Samorim tenha deixado o Gama dizer 
que viera «descobrir» aquelas terras, de todos conhecidas, e insinua confusão dos tradutores árabes.

Mas o Samorim pensava

que estava tanto a descobrir aquela gente como a nossa gente o estava a descobrir a ele.

O comércio tinha que crescer

e a concorrência era proveitosa.

Não era nem um combatente da liberdade nem um leal colonizado: era o Samorim!

(“1498: Modernidade do Samorim” [MENDES, 2011, p. 127])

Assim, este Samorim "moderno" representa um pragmatismo diplomático e económico usado enquanto apelo à desconstrução do complexo pós-colonial. Como se pode ver, LFCM não recua perante o confronto intelectual com as próprias armas que detém, o verso. A introdução de uma dimensão crítica e de debate no poema, para a qual não se coíbe de apresentar nomes (como o do historiador indiano Sanjay Subrahmanyam) e de emprestar voz às posturas em confronto, será sem dúvida uma das dimensões mais interessantes deste livro.

Nesta visão descomplexada, quer em relação à Ásia, quer em relação a Portugal, torna-se absurdo pedir desculpas pela História - "A História (...)/ serve agora para pedirmos desculpa do passado,/ dispensando-nos de olhar para o presente", (MENDES, 2011, p. 43). E é assim que se assume, sem grandes problemas, que este livro trata, não apenas da Ásia, mas também de uma Ásia que é Portugal, isto é, sobre as marcas que a cultura portuguesa lá deixou e que obrigam a uma singular arqueologia imperial. É sobre isto que também falam, de um modo mais determinante ainda, o ciclo macaense de Couto Viana, bem como a parte oriental da poesia de José Augusto Seabra (1937-2004), com Poemas do Nome de Deus (1990) e O Caminho Íntimo para a Índia (1999), aliás antecessor de LFCM em New Delhi. Todavia, para além dos lugares, monumentos e inscrições de que esta arqueologia é feita, os próprios poetas portugueses que calcorrearam a Ásia são também recuperados como sinais desse Oriente português. E é agrupando todas essas referências culturais que Lendas da Índia se revela como o elo mais recente de uma antiga cadeia.

Com efeito, Luís de Camões, Fernão Mendes Pinto, Manuel Maria Barbosa du Bocage, António Patrício, Camilo Pessanha, Alberto Osório de Castro, Venceslau de Morais e, mais recentemente, Ruy Cinatti, Armando Martins Janeira, António Manuel Couto Viana e José Augusto Seabra constituem uma linhagem de autores que manifesta uma ligação simultaneamente vivencial e estética ao Oriente português. Esta tem vindo a depender sobretudo de funções diplomáticas e/ou representativas do Estado Português (desde o próprio Camões, que em Macau foi "provedor-mor de defuntos e ausentes” até ao diplomata José Augusto Seabra), do exercício do Direito e de outras funções outrora estreitamente ligadas ao aparelho 
colonial. Aos nomes atrás citados, acrescente-se ainda LFCM, jurista e diplomata (tal como a maioria dos atrás referidos), assumindo textualmente a errância própria da sua carreira (vejam-se os poemas sobre Espanha, Hungria, Brasil) e provando que esta via de relação entre Portugal e a Ásia ainda não tem os seus dias contados.

Mas não é apenas a profissão e a vivência directa de um espaço comum que une aqueles autores. Trata-se de uma tradição com os seus tópicos particulares, directamente relacionados com as biografias dos autores, que como que performatizam a sua errância pela Ásia, mitificando-a à luz dos seus antecessores. Assim, uma das características desta poesia tem sido a constante mediação de referências literárias portuguesas para entender o próprio Oriente. Este tipo de intertextualidade pode, talvez em muitos dos casos, ser lido à luz do mecanismo, apontado por Edward Said em 1979, de legitimação do discurso orientalista pela referência à autoridade de outros plumitivos. De qualquer maneira, e mesmo que não seja esse o caso, é irresistível, para um poeta português que habite na Índia e que sobre ela escreva, falar de Camões (passim, mas sobretudo p. 61, 62 e 95). Indirectamente, também Bocage aparece (p. 56) e até mesmo Pessanha (p. 15 e 56), puxando para uma geografia luso-oriental mais alargada.

No entanto, em LFCM esta autoinscrição na linhagem não implica a construção de uma poesia efectivamente orientalista, no sentido forte, isto é, saidiano do termo. Em si, ela pode ser lida pelo lado da homenagem. Há, contudo, uma ambiguidade neste livro: se, por um lado, LFCM dá literalmente voz ao outro, e tem vários cuidados ideológicos com este, ao mesmo tempo também tende a observar a Ásia com uma lente sem dúvida portuguesa. Assim, tem razão António Guerreiro ao assinalar uma "sábia prudência no que diz respeito a ingénuos entusiasmos por experiências exóticas orientais" (GUERREIRO, 2011, p. 22), mas engana-se ao considerar a inscrição de Camões e de Pessanha como filtros de defesa contra esse mesmo orientalismo. Pelo contrário, tal como Venceslau e Pessanha fizeram com Camões e Mendes Pinto, Janeira com Mendes Pinto e Venceslau, Couto Viana com Patrício, Pessanha e Camões (etc., e em acumulação), estas relações são a construção de uma cadeia de representação do Oriente por portugueses, que tende a relacionar um afecto pelas coisas asiáticas com uma obsessão por encontrar (e por vezes sobrepor) Portugal e as marcas da sua cultura imperial ao contexto asiático, no que pode transparecer uma efectiva dimensão orientalista. Desta maneira, homenagear Camões e Pessanha não é obviamente em si mesmo um gesto orientalista, mas arrasta consigo implicações orientalizantes vindas da tradição onde tal homenagem se quer inscrever.

Veja-se, a respeito desta questão, a seguinte passagem de Lendas da Índia onde o sujeito se confessa herdeiro da tradição portuguesa de um Oriente fatal que, só por si, tem a capacidade de provocar o surgimento dum grande poeta ou de o reduzir a cinzas: 
Pessanha, onde está a luz do nosso pais perdido?

Quando descobriremos o nosso Ocidente,

nós que de tanto Oriente fomos embriagados

como perus para a ceia da Poesia?

$(\ldots)$

O Oriente desfaz-nos, por certo, mas pode

tornar-nos aves fénix

ou galinhas de capoeira!

(“Invocação a Pessanha” [MENDES, 2011, p. 56])

Por outro lado, intervém aqui, tal como em José Augusto Seabra, a poética do mistério e da ignorância: os deuses hindus são símbolos transcendentes e impenetráveis (cf. MENDES, 2011, p. 31) que espelham a ignorância (assumida) do ocidental perante o misterioso Oriente (conhecido tópico que vem da literatura europeia dos séculos XVIII-XX acerca do Oriente), ignorância essa que por vezes surge sob a forma do cansaço:

\section{(...) o Oriente dói,}

alheio aos nossos conceitos estafados,

desfeitos pelas chuvas da monção

ou dispersos pelos ventos do deserto.

(“Um orientalista confessa-se” [MENDES, 2011, p. 36])

E é assim que, nesta necessidade de compreender um Oriente poderoso, mas resistente à compreensão, LFCM chega a uma solução provisória para o enigma da Índia, que o autor claramente sente como tal ("Três anos a conviver contigo/ e nunca chegarei a entender-te! (...)// Como é ser misterioso sem ser misterioso?/ Como é ser inacessível sem ser recatado?" [MENDES, 2011, p. 121]). Assim, para resolver o paradoxo entre a Índia dos deuses misteriosos e a Índia hiper-tecnológica, surge a imagem simbólica da Índia-Medusa, de mil formas. Note-se que é o recurso a uma instância mítico-simbólica de proveniência greco-latina que resolve o que começa como precaução de autodefesa contra uma alteridade inapreensível. Assim, embora feita de gente real e "igual a nós", a Índia acaba por ser hipostasiada enquanto instância ("Mãe Îndia”) afinal irrepresentável, que age e se move através dos seus milhares de avatares-heterónimos (MENDES, 2011, p. 121) nos quais ela está simultaneamente presente e inacessível (“Como é ser misterioso sem ser misterioso?/ Como é ser inacessível sem ser recatado?” [MENDES, 2011, p. 121]).

Em conclusão, talvez uma expressão, que é em boa medida um contra-senso, como orientalismo esclarecido (por partir de uma consciencialização e de precauções que nos remetem já para uma esfera (pós)-orientalista, conforme sugerido) seja uma formulação útil para explicar a singularidade de certas dimensões de uma obra que, ao mesmo tempo que 
dialoga, como vimos, com uma tradição portuguesa de escrita poética sobre o Oriente, nela criticamente se inscreve. Isto é, há com efeito em LFCM, em relação a todos aqueles autores supracitados, uma diferença que salta à vista: sendo glosados muitos dos mesmos temas e tópicos, isto é feito com uma consciência crítica que não permite que coloquemos, pelo menos nunca duma forma linear, o autor num discurso orientalista, no sentido saidiano do termo. Com efeito, em LFCM é plasmado um discurso pós-orientalista no campo da poesia portuguesa, sobretudo na medida em que é um discurso esclarecido que se precavém contra certas tradições de representação distorcida. Contudo, este discurso acaba afinal sofrendo de uma fértil ambiguidade na forma como tange a lira luso-oriental e suas especificidades. Isto é, é pela via da inscrição numa tradição poética portuguesa que surgem certas implicações orientalizantes próprias da linhagem e que necessariamente, por via desta, estão presentes, mostrando assim que há uma tradição poética de relação entre Portugal e o Oriente de boa saúde num contexto de pós-modernidade já muito distante do de Pessanha ou de Morais.

\section{REFERÊNCIAS BIBLIOGRÁFICAS}

GUERREIRO, António. Em terra estrangeira. Atual-Expresso, 30 de Julho de 2011, p. 22.

MENDES, Luís Felipe Castro. Lendas da Índia. Lisboa: Dom Quixote, 2011.

Recebido para publicação em 15/05/12.

Aprovado em 15/06/2012. 